\title{
POLICE LEARNING: EXAMINING THE USE OF SIMULATIONS IN POLICE TRAINING AND THE ASSOCIATED LEARNING THEORIES D. Hanna, A. Ferworn, A. Abhari
}

\author{
Ryerson University (CANADA) \\ dhanna@ryerson.ca, aferworn@ryerson.ca, aabhari@ryerson.ca
}

\begin{abstract}
In addition to the cost savings, technology such as e-learning, hybrid learning and simulations are tools that are used to equip police force with the competencies and skills needed to protect the public and respond to the changing demographics. That is, the future of police training will be geared towards developing competencies to support existing training for police and the recruitment process that relies on technology and integrated crisis management systems. Simulations, robotics and reallife situations are vital in preparing the first responders and decision makers with the skills and competencies needed to respond effectively to a crisis. The successful design of the training strategies will provide police force with tactics that will enable them to offer the training in a suitable delivery medium.
\end{abstract}

In this paper, we explore the use of simulations and virtual environments in police training, investigate examples of integrated simulation architectures and list how the various learning theories apply to police training. While there has been many research done around the use of simulations and virtual training in police force training, only very few provide information about the use of integrated simulation architecture and the application of learning theories in their training. Thus, comes the novelty of this paper.

Keywords: Virtual, Simulation, Police, Learning Theories, Public Safety, Crisis Management.

\section{INTRODUCTION}

In crisis management, human behavior constitutes a fundamental aspect in responding to the crisis; the speed and efficiency of the response often get affected by the difficulty of the context of the operation. Therefore, training in this area plays a major role in preparing the crisis manager to manage the emotional aspects that lead to the decision making in these critical situations. Thus, the training needs to address the multiple contexts in which the crisis happens in and has to take into the account interdependency between different life-threatening arrangements. Since it is vital to gain high-level strategic choices and besides the ability to apply crisis management practices, simulation exercises become central in training the crisis managers in gaining the needed skills to respond critically to these events. The training will enhance the responders' ability to efficiently and quickly make decisions and anticipate possible consequences of their actions through flexible and revolutionary reasoning in responding to the crisis. Additional, understanding how police learn, as adult learners, will enable designers and scientists in building the relevant learning technology tools.

\section{SIMULATIONS AND INTEGRATED SYSTEMS IN POLICE TRAINING}

In a case study for firearm training, the RCMP compared result between officers trained through simulators and live firearms. They found that officers trained on simulators achieved a higher mean score in the final firearm qualifying reshoot test [1]. They concluded that "Simulated training allows for the transferability of skills for basic decision making." As well, RCMP investigated training using virtual worlds. École nationale de police du Québec (ENPQ) in Quebec integrated technology at various training levels utilizing a free Learning Management System (Moodle) to provide 24/7 access to training materials. Additionally, with a focus on knowledge transfer and independent learning, ENPQ developed competency-based training modules in which the trainer engages with course materials and receives immediate feedback. Virtual simulators are an integrated part of their training, specifically for cookpot driving. ENPQ is looking to add lightweight tabletop simulators in the future. 
[2] presented a case study of a collaboration between a higher education institute and a police division in the UK, named the "The Leicestershire Partnership Scheme." The partnership resulted in building a police-specific training course that is built on the use of reflective exercises to enhance critical reflections, simulation exercises to augment decision-making skills and an inter-professional and multidisciplinary focus to widen their academic knowledge.

There are many examples of using technology in military and civil training, specifically in the area of simulation and gaming which provides an opportunity to experience real life situations in almost real events [3]. In 2011, The European Commission Research and Development (EU R\&D) funded 46 projects related to gaming and simulations. Currently, the EU R\&D have several projects on robotics, simulation and gaming for crisis management. The organization funded over 100 collaborative projects on innovative research in the area of robotics and its use in the areas of search, rescue, retrieval, inspection and monitoring, and much more [4].

In crisis management, human behavior constitutes a vital aspect in responding to the crisis; the speed and efficiency of the response often get affected by the difficulty of the context of the operation. Therefore, training in this area plays a major role in preparing the crisis manager to manage the emotional aspects that lead to the decision making in these critical situations. Thus, the training needs to address the multiple contexts in which the crisis happens in and has to take into the account interdependency between different life-threatening infrastructures [3]. Since it is important to gain highlevel strategic choices and besides the ability to apply crisis management procedures, simulation exercises become central in training the crisis managers in gaining the needed skills to respond critically to these events. The training will enhance the responders' ability to efficiently and quickly make decisions and anticipate possible consequences of their actions through flexible and revolutionary reasoning in responding to the crisis.

The authors in [3] presented the PANDORA's concept, which presents advanced training environment for crisis scenarios. These scenarios take into account two important aspects during training which are fundamental in the decision-making process. First, it fills the gap between the table-top packaged simulations which are very expensive and second, real-world situations and scenarios. That is accomplished through the use of a simulation which is realistic and takes the environment, where actions happen, into account. Thus, it can reproduce a realistic emotional status which is represented in the system as the planning and sensing acts. Figure1 illustrates the structure of the different levels of decision makers in crisis management. The three levels correspond to different roles of the crisis decision makers in an integral environment that combine sensing, planning and acting. To explain, sensing is practiced in behavior simulation and modeling, then the trainer uses planning in constructing the crisis simulation and finally the trainee acts through technology. Below are the details related to the operational, tactical and strategic levels as listed in [3]:

1. The operational level (Bronze): This is for responders on grounds at the first level of the crisis. They perform practical activities and actions, the outcomes of their actions are then monitored and communicated to higher levels.

2. The tactical level (Silver): In this level, staff members are located close but not within the crisis areas. They are responsible for transforming high-level tactical decisions into actions. This is done by assigning tasks and resources down to the operational level. The expected results from this level are observed and measured for efficiency by the strategic team.

3. The strategic level (Gold): The commanders at this level identify the key issues of a critical situation and prioritize required activities. They decide on strategies for resolving the crisis and communicate them to the lower levels for implementation. 


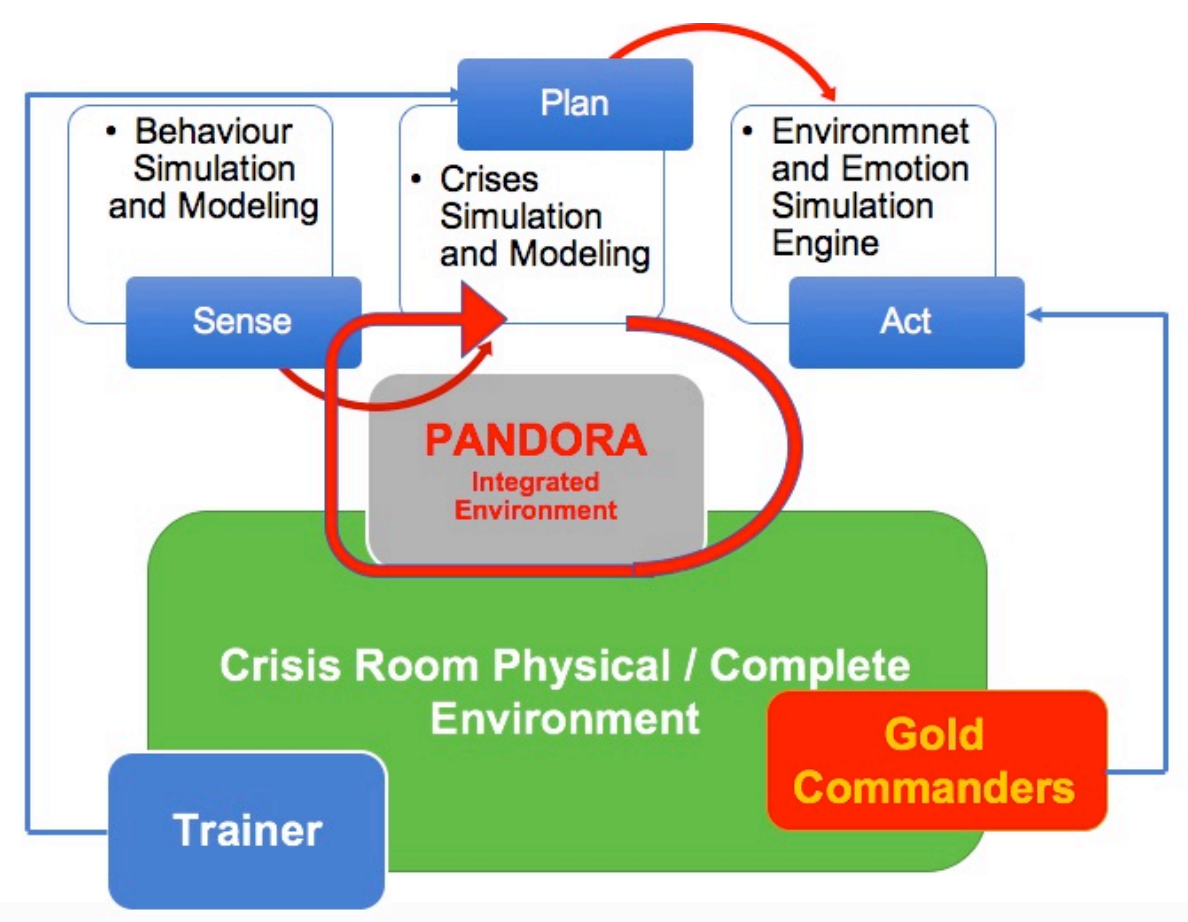

Figure1: Different decision makers in crisis management. The figure shows three different levels corresponding to different roles of crisis decision makers adapted from [3].

[5] suggested an architecture for integrated modeling and simulation for emergency response. The concept is that in crisis, there could be multiple scenarios that result from the initial crisis. For example, in an explosion in a commercial building, the impact itself could affect the structure, the wind could affect the direction of fire, traffic will be affected and the response teams may act differently based on each impact. Therefore, they recommended the use of the integrated system that takes into consideration the various results of a crisis. This system will be constructed on existing simulations for each area. The challenge is to develop communication method among these simulators to ensure a dynamic response. The main advantage is that each simulation system can build on the strength of the other systems. As a result, using the system will provide the trainee with a much more informed decision as they respond to a disaster. For this proposed integrated system to work efficiently and to avoid the challenges associated with the integration of various systems, the authors introduced a number of components and interfaces. A distributed simulation community led by Defense Modeling and Simulation Office (DMSO) was used to standardize the high-level architecture (HLA) and they applied standards for virtual reality modeling related to the advanced visualization of simulation results.

To ensure that the technology equipment used by law enforcement units are safe, reliable and perform according to established minimum requirements, The National Institute of Justice (NIJ) in the US, established standards and testing programs. These programs support the development of equipment standards and related compliance appraisal programs that address these needs [6]. NIJ's strategy in developing technology standards rely on:

- Partnering with the Private Sector

- Forming Special Technical Committees and Advisory Working Groups

- Developing Standard Packages

- Listening to Stakeholders and Dissemination Process

- Revising Existing Standards

For example, NIJ developed standards on Public Safety Bomb Suit Standard, Standard Practice for Measurement of Body Armor Wearers, portable Bomb X-Ray, Handheld Metal Detectors, and more. These standards need to be considered in the development of training tools including simulators, robots and explosive devices for testing purposes. 
The Justice Institute of British Columbia (NIBC) offers a comprehensive training program for police training. The topics include a wide variety of topics on leadership, communication, ethics, conflict management, psychology ...etc. As well as hands-on training in crisis, rescue, emergency and security management. The training varies from self-based individual training modules to group learning [7]. Also, the curriculum includes face-to-face learning, hybrid and online learning environments. Based on the descriptions of the topics, and the learning environments, it is evident that the training is based on behaviorist, social learning and adult learning theories. The assumption is that adult learning theories are incorporated based on the population and age group. Knowing this, and based on the behavioral simulation model presented in the PANDORA model, in the next part of this paper, we discuss the implication of the various learning theories on police training. In addition, we will discuss its consideration in planning and designing training tools for police force.

The report by [1] states that the Victoria Police in Australia transformed part of their training to elearning, a move that matched the police officers' learning styles, improved efficiencies, and costs. Additionally, the report lists simulators as an effective way to train police officers. Durham Police identified several concepts like appropriateness, accessibility and affordability as well as learnercentered as essential elements to any training.

\section{LEARNING THEORIES IN RELATION TO POLICE TRAINING}

In the report on the State of E-Learning in Canadian Policing [8], the Canadian Police Knowledge Network (CPKN) emphasized the importance the use of technology and innovation in police training and how it may enhance performance and skills as well as reduce cost. The report provided examples of current technologies used in police training. Some of these examples are: "electronic databases, driver and vehicle information, missing persons' alerts, data on unsolved crimes; electronic speed radar guns; computer crime mapping, mobile laptop computers; portable crime scene technology; mobile evidence cataloguing technologies; advanced GPS tracking systems; digital photos/videos and radio frequencies to coordinate first responders; and sophisticated surveillance systems" (p.4). Most importantly, the report stated in the recommendations that there should be a need to shift training concepts and models, a plan to use technology in transferring knowledge from retired officers to new recruits and leverage technology to keep up with the rapidly changing skills needed for on the job tasks.

\subsection{Behaviorist Learning Theory}

In the behaviorist learning theory, the learner reacts to the environment and responds properly after being exposed to a specific stimulus. Tools to use in the learning process are instructional cues, practice and reinforcement which help in determining goals and outcomes. The behavior can be learned, it can also be unlearned and relearned [9] [10]. The practical application of knowledge in this learning environment is by using videos and simulations using live actors and online activities.

\subsection{Cognitive Learning Theory}

The cognitive learning theory assumes that "Learning is an active process where meaning and understanding built from experiences" [11] (p. 6). Factors that influence learning are environmental conditions and instructional explanations which should be built on the learners' attitude, previous experiences and beliefs. Memory is very important for the learning process. Information is organized in the memory in a meaningful way to facilitate the retrieval of the information [10]. The information is received in the memory through networks that link to other information in memory; information is stored in the short-term memory (STM), transferred to the long-term (LTM) memory, or it gets lost [12]. Technology is used by designing tools based on elaboration and scaffolding, which means that the simulations and integrated systems need to be revealed step-by-step in phases or segments.

\subsection{Social Learning Theory}

The social learning theory offers insights about how people learn in a social environment as a group. Based on this theory, learning occurs when each learner is engaged in social activities and knowledge is culturally and socially constructed in which people learn from one another, using modeling, observation, and imitation [13] [14]. Additionally, learners learn through social interactions with more knowledgeable learners and collaboration with other learners through a community of practice [13]. As this theory is described as a bridge between behaviorist and cognitive theories, memory is a key in 
retaining and encoding information. Information is based on observation and the learning happens through effective modeling starting with attention, retention, reproduction and motivation [14]. As cited in [13], Schunk explained that the best teaching and learning strategies associated with this theory are, problem-based learning, shared teaching, peer collaboration and learning with others

\subsection{Adult Learning Theory}

Finally, as the majority of the police force are considered adult learners, it is important to explore the characteristics of adult learning theories and how it relates to police learning. In adult learning theories, the learner is involved and takes responsibility for his/her learning process. The learner selfreflect, gathers information, collaborates with others and is self-directed. Factors that influence learning are past life and work experiences, previous knowledge and past learning experiences [15]. Information is most likely remembered when learning is based on the application exercises and discussions [16]. An effective way of teaching and learning associated with this theory would be to utilize different learning tools, present information in various formats and media (podcasts, handouts, online modules, videos) and design courses with open-ended projects, more student choice, experientially based assignments and interactive materials [17]. One of the learning strategies associated with adult learning is the effective elaboration. It helps learners to remember information in the long term and use it in situations where it might be appropriate. It is also a strategy that could be taught easily, and used with learners from different age groups. Designers need to design reflective activates that could improve the student's intrapersonal awareness.

\section{CONCLUSIONS}

In conclusion, it is evident that first responders, police force and military personnel depend on simulations. There are various ways to use simulations; some are over the shelf ready-made and other need to be designed based on specific needs, which of course comes with a price. In police training, using integrated architectures and frame work of various simulators may enhance their skills and decision making. Finally, in police training we need to consider the various learning theories in designing instruction and tools; these theories could vary from behaviourist, cognitive, social learning and adult learning. Each theory provides insights on how to design technology enhanced instruction and all could be used in an integrated system to provide various learning experiences. Future work is needed to relate these theories to existing technology learning tools, measure the success of its application and compare results from each. Part of the learning tools could be the automated analysis of open learning simulations that could be rated based on the trainees' feedback.

\section{REFERENCES}

[1] Network CP. ECONOMICS OF POLICING: POLICE EDUCATION AND LEARNING SUMMIT Summary Report. Retrieved from https://www.publicsafety.gc.ca/cnt/rsrcs/pblctns/plc-Irnngsmmt/index-en.aspx

[2] Christopher S. The quantum leap: Police recruit training and the case for mandating higher education pre-entry schemes. Policing: A Journal of Policy and Practice. 2015 Jul 17;9(4):388404.

[3] Dastbaz M, Cesta A. Simulations for Crisis Management-PANDORA's Box. In Intelligence Management 2011 (pp. 111-131). Springer London.

[4] Europa.eu. [Online]. Available from: https://ec.europa.eu/digital-singlemarket/en/robotics [Accessed 12 March 2017].

[5] Jain S, McLean CR. An architecture for integrated modeling and simulation for emergency response. InlIE Annual Conference. Proceedings 2004 Jan 1 (p. 1). Institute of Industrial and Systems Engineers (IISE).

[6] Nij.gov. [Online]. Available from: https://nij.gov/topics/technology/standardstesting/Pages/welcome.aspx. [Accessed 24 March 2017].

[7] Jibc.ca. [Online]. Available from: https://catalogue.jibc.ca/Lists/Courses/CoursesBySubject.aspx [Accessed 24 March 2017] 
[8] Policecouncil.ca. [Online]. Available from: http://www.policecouncil.ca/wpcontent/uploads/2013/03/State-of-E-Learning-in-Canadian-Policing-2010.pdf [Accessed 23 September 2017].

[9] Orey M. Emerging perspectives on learning, teaching and technology. CreateSpace; 2010.

[10] Ertmer PA, Newby TJ. Behaviorism, cognitivism, constructivism: Comparing critical features from an instructional design perspective. Performance improvement quarterly. $1993 \mathrm{Dec}$ 1;6(4):50-72.

[11] Wildman TM, Burton JK. Integrating learning theory with instructional design. Journal of Instructional Development. 1981 Mar 1;4(3):5-14.

[12] Ormord, J, Schunk, D, Gredler, M. Learning theories and instruction . New York: Pearson; 2009.

[13] Kim B. Social constructivism. Emerging perspectives on learning, teaching, and technology. 2001 Oct;1(1):16.

[14] Learning-theories.com. [Online]. Available from: http://www.learning-theories.com/sociallearning-theory-bandura.html.

[15] Conlan J, Grabowski S, Smith K. Current trends in adult education. Emerging perspectives on learning, teaching and technology. 2003.

[16] Medscape.com. [Online]. Available from: http://www.medscape.com/viewarticle/547417_2.

[17] Foley G, editor. Dimensions of adult learning. McGraw-Hill Education (UK); 2004. 